\title{
Interação entre endomicorrizas e frutíferas nativas (Myrtaceae) no Rio Grande do Sul
}

\author{
Interaction between endomycorrhizae and native fruit tree (Myrtaceae) in Rio \\ Grande do Sul state
}

\author{
Daiane Silva Lattuada ${ }^{\mathrm{I}}$, Sandra Rieth ${ }^{\mathrm{II}}$, \\ Marina Martinello Back ${ }^{\mathrm{III}}$, Paulo Vitor Dutra de Souza ${ }^{\mathrm{IV}}$
}

\begin{abstract}
Resumo
A interação entre espécies vegetais e micorrizas arbusculares (MA) favorece o desenvolvimento de mudas. Para verificar esta interação conduziu-se estudo, em duas etapas, entre três espécies de micorrizas arbusculares (Glomus etunicatum, Gigaspora margarita e Scutellospora heterogama), além de uma testemunha e três espécies de Myrtaceae nativas no Sul do Brasil: Eugenia pyriformis Cambess, Myrcianthes pungens (O. Berg) D. Legrand) e Psidium cattleyanum Sabine na produção de mudas. Na etapa de sementeira, sementes das espécies vegetais foram semeadas em bandejas multicelulares, preenchidas com substrato autoclavado e $1 \mathrm{~g}$ de inóculo/célula de cada espécie de MA estudada. Nesta etapa avaliaram-se a emergência e o desenvolvimento inicial das plântulas (altura e número de folhas por muda), aos 125 dias após a semeadura. Na etapa de viveiro, as mudas foram transplantadas para sacos de polietileno preto (5 L), contendo substrato comercial desinfestado. 480 dias após o transplante, avaliaram-se o desenvolvimento vegetativo das plantas e a colonização pelas MAs nas raízes. Na fase de sementeira, as MAs colonizaram as raízes, mas não alteraram emergência e desenvolvimento inicial das plântulas. Após o transplante para recipientes maiores todas as espécies de MAs foram eficientes quando comparadas à testemunha, proporcionando incrementos médios na ordem de $135 \%$ na altura, $195 \%$ no número de folhas, $299 \%$ no número de brotações e $209 \%$ na área foliar. Os resultados confirmam a efetiva simbiose entre as espécies florestais e as endomicorrizas estudadas.
\end{abstract}

Palavras-chave: Frutíferas nativas; Fungo micorrízico arbuscular; Viveiro florestal

\begin{abstract}
The interaction between plant species and endomycorrhizas (AM) favors the development of seedlings. In order to verify this interaction, it was developed a two-step research about of three species of arbuscular mycorrhizas (Glomus etunicatum, Gigaspora margarita and Scutellospora heterogama), as well as one control and three native Myrtaceae species in southern Brazil: Eugenia pyriformis Cambess, Myrcianthes pungens (O. Berg) D. Legrand) and Psidium cattleyanum Sabine in the production of seedlings. In the sowing stage, seeds of the plant species were sown in multicellular trays, filled with autoclaved substrate and $1 \mathrm{~g}$ of inoculum/cell containing each AM species studied. In this stage the emergence and initial development of the seedlings (height and number of leaves per seedling) were evaluated at 125 days after sowing. In the nursery stage, seedlings were transplanted to black polyethylene bags $(5 \mathrm{~L})$ containing disinfested commercial substrate, 480 days after transplantation, the vegetative development of the plants was evaluated colonization by the AMs in the roots. In the sowing phase, the AM colonized the roots, but did not alter the emergence and initial development of the seedlings. After transplantation to larger containers all AM species presented better performance when compared to the control, providing mean increments in the order of $135 \%$ for height, $195 \%$ for number of leaves, $299 \%$ for number of shoots and $209 \%$ for leaf area. Indicating the efficiency of the AMs in development acceleration of the plants and therefore the effective symbiosis between the forest species and the endomycorrhiza studied.
\end{abstract}

Keywords: Native fruit trees; Arbuscular mycorrhizal fungi; Forest nursery

Engenheira Agrônoma, Dra‥, Pesquisadora do Departamento de Diagnóstico e Pesquisa Agropecuária, Secretaria da Agricultura, Pecuária e Desenvolvimento Rural do Rio Grande do Sul, Estr. Fazenda Souza, s/n, CEP 95001-970, Caxias do Sul (RS), Brasil. daiane-lattuada@agricultura. rs.gov.br (ORCID 0000-0002-8892-5811)

Engenheira Agrônoma, MSc., Extensionista Emater/Ascar-RS, Rua Jorge Fett, 84, CEP 95870-000, Bom Retiro do Sul (RS), Brasil. srieth@emater. tche.br (ORCID 0000-0002-0642-8492)

III Engenheira Agrônoma, MSc., Doutoranda no Programa de Pós-graduação em Fitotecnia, Faculdade de Agronomia, Universidade Federal do Rio Grande do Sul, Av. Bento Gonçalves 7712, CEP 91540-000, Porto Alegre (RS), Brasil. backmarina@gmail.com (ORCID 0000-0002-5377-3790)

IV Engenheiro Agrônomo, MSc., Dr., Professor do Departamento de Horticultura e Silvicultura, Faculdade de Agronomia, Universidade Federal do Rio Grande do Sul, Av. Bento Gonçalves, 7712, CEP 91540-000, Porto Alegre (RS), Brasil. pvdsouza@ufrgs.br (ORCID 0000-0003-2900-3638) 


\section{Introdução}

A exigência da conservação da vegetação nativa é crescente, devido, especialmente, à intensificação dos problemas ambientais, o que vem despertando o interesse pelo uso de espécies florestais nativas brasileiras, proporcionando demanda por mudas, as quais constituem insumo básico nos programas de recuperação ou conservação de ecossistemas. Neste cenário, podem ser utilizadas espécies de frutíferas nativas, pois além de participarem do processo de restauração, contribuem para a alimentação da fauna local. Dentre estas, àquelas da família Myrtaceae destacam-se também pelo seu potencial de uso doméstico e comercial. Contudo, muitas dessas necessitam de pesquisas que aperfeiçoem sua produção de mudas a baixo custo e com qualidade (JOSÉ; DAVIDE; OLIVEIRA, 2005). De acordo com Silva; Peixoto; Junqueira (2001), o uso de substratos adequados associados ao emprego de fungos micorrízicos arbusculares, contribui para a formação de mudas com qualidade superior.

Ainda, o grande potencial econômico das espécies frutíferas nativas representa, especialmente ao agricultor familiar, uma possibilidade de diversificação de renda e possibilita a produção de frutos diferenciados, suprindo a carência do mercado consumidor que está sempre à procura por novidades. Espécies de Myrtaceae nativas no Brasil produzem frutos de sabor e aromas exóticos, além de terem potencial para uso medicinal, para o paisagismo e para a recuperação de áreas degradadas (LOPES, 2009).

Dentre os gêneros desta família botânica que englobam espécies frutíferas com potencial, quatro merecem destaque: Acca, Eugenia, Myrciaria e Psidium. São representantes do gênero Acca, a Feijoa ou Goiabeira-Serrana (Acca sellowiana (O. Berg) Burret); do gênero Eugenia, a Pitangueira (Eugenia uniflora L.) e a Uvaieira (Eugenia pyriformis Cambess); do gênero Myrciaria, o Guabijuzeiro (Myrcianthes pungens (O. Berg) D. Legrand) e do gênero Psidium, o Araçazeiro-Vermelho (Psidium cattleyanum Sabine) (MANICA, 2002). Raseira et al. (2004) salientam que, embora haja boas perspectivas para comercialização destas frutíferas, ainda são necessários estudos que viabilizem a domesticação destas, tais como: metodologias para a propagação e produção comercial de mudas, estudos de manejo e condução de pomares, além dos aspectos pós-colheita dos frutos, entre outros.

Em relação à produção de mudas, um dos aspectos a ser explorado para Myrtaceae é a interação entre as espécies vegetais e as micorrizas arbusculares (MAs). Registros indicam que esta interação favorece uma rápida formação, redução no tempo de aclimatização e maior homogeneidade de mudas durante o crescimento inicial no campo (LOCATELLI; LOVATO, 2002). As MAs são amplamente reconhecidas pelo efeito positivo que proporcionam no crescimento da planta, no aumento da absorção de nutrientes, especialmente o fósforo, pelo maior volume de solo explorado, acúmulo de carboidratos nos tecidos e por conferirem maior tolerância aos estresses bióticos e abióticos (NUNES et al., 2008; RAMOS et al., 2011), além de aumentar a tolerância aos patógenos radiculares e reduzir o nível de aplicação de fertilizantes após o transplante (NOGALES et al., 2009). Segundo Locatelli; Lovato (2002), têm sido relatadas diferenças entre as espécies de MAs na promoção do crescimento e do desenvolvimento de uma mesma espécie vegetal, sendo interpretadas como especificidade (SILVEIRA; SOUZA; KOLLER, 2002) ou compatibilidade funcional (AGUIAR et al., 2004) entre o hospedeiro e o fungo. Portanto, aspectos da relação fungo-planta devem ser considerados para o estabelecimento da simbiose micorrízica. Neste sentido, há necessidade de se ampliar as pesquisas nesta área, considerando os benefícios reconhecidamente consolidados em outras frutíferas, pela micorrização, avaliando também as espécies vegetais de interesse, os isolados fúngicos e suas respectivas combinações. Os trabalhos sobre a associação entre MAs e espécies da família Myrtaceae, até o momento, tratam da associação fungo-planta em ambientes naturais (SILVA et al., 2009; LOPES, 2009; CAMPOS et al., 2011), sendo o presente estudo direcionado para produção de mudas em cultivo monoespecífico com fungos micorrízicos arbusculares.

Desta forma, este trabalho objetivou verificar a interação entre três espécies de micorrizas

Ci. Fl., Santa Maria, v. 29, n. 4, p. 1726-1736, out./dez. 2019 
arbusculares (Glomus etunicatum, Gigaspora margarita e Scutellospora heterogama) e três espécies de Myrtaceae nativas no Sul do Brasil (Eugenia pyriformis Cambess, Myrcianthes pungens (O. Berg) D. Legrand, e Psidium cattleyanum Sabine) na fase de formação da muda.

\section{Material e métodos}

O experimento foi desenvolvido em casa de vegetação $\left(30^{\circ} 04^{\prime} 26,04^{\prime \prime}\right.$ e e $51^{\circ} 08^{\prime} 7,08^{\prime \prime} \mathrm{W}$; $46,97 \mathrm{~m}$ de altitude), durante 16 meses. Foram avaliadas três espécies de micorrizas arbusculares (MAs): Glomus etunicatum, Gigaspora margarita e Scutellospora heterogama mais a testemunha (ausência de MAs). As espécies vegetais avaliadas foram: Uvaieira (Eugenia pyriformis), Guabijuzeiro (Myrcianthes pungens) e Araçazeiro vermelho (Psidium cattleyanum) (SISGEN no AA5F77E).

Os inóculos das MAs utilizadas, pertencentes ao banco de micorrizas do Departamento de Horticultura e Silvicultura da UFRGS, foram previamente multiplicados em cultura de vasos (recipiente semirrígido de $1 \mathrm{~L}$ ), os quais foram preenchidos, dois terços, com areia autoclavada (2 autoclavagens de 1 hora, à 1 ATM, com intervalo de 24 horas), disposto $3 \mathrm{~g}$ de inóculo puro de cada MA isoladamente, preenchido mais $1 \mathrm{~cm}$ de areia e depositadas as sementes de Avena sativa. Por fim, completou-se o volume total do recipiente com areia. Os vasos permaneceram em casa de vegetação com irrigação manual e isolados a fim de evitar contaminações com outros microrganismos. Após um mês da semeadura e inoculação das MAs foram feitas aplicações semanais com solução nutritiva Long-Ashton (BRUNDRETT; MELVILLE; PETERSON, 1994) modificada (10 \% fósforo), em uma quantidade de $10 \mathrm{~mL}$ de solução por vaso. Após quatro meses de cultivo, cessou-se a irrigação e a areia com fragmentos de raízes foram secos e armazenados a $4^{\circ} \mathrm{C}$, até utilização.

Sementes das espécies florestais foram removidas de frutos maduros e submetidas à lavagem com água destilada e posterior secagem à sombra por 24 horas. Imediatamente após, foram semeadas em bandejas multicelulares ( 2 sementes por célula, células de $25,09 \mathrm{~cm}^{3}$ ), previamente desinfestadas com hipoclorito de sódio $(2 \%)$, contendo substrato autoclavado (Carolina Soil ${ }^{\circledR}$ - composto a base de turfa e vermiculita, pH 5,0 $\pm 0,5$ e CE 0,4 $\pm 0,3 \mathrm{mS} / \mathrm{cm})$. Anteriormente à semeadura, adicionou-se $1 \mathrm{~g}$ de inóculo de MAs por célula, em uma camada disposta $1 \mathrm{~cm}$ abaixo das sementes. O inóculo era constituído por areia grossa e fragmentos de raízes de aveia-preta (Avena sativa) colonizadas com MAs. Cada bandeja (50 células) foi usada para uma única espécie de MAs, e aquelas que continham as testemunhas, não foram inoculadas. As bandejas foram isoladas, na parte inferior e lateral, com sacos de polietileno e distanciadas cerca de $50 \mathrm{~cm}$ umas das outras, a fim de evitar contaminação de inóculo dos tratamentos vizinhos.

Após 125 dias da semeadura (DAS), avaliou-se o percentual de emergência, a altura e o número de folhas por planta. Em seguida, as mudas foram transplantadas para sacos de polietileno preto (5L) contendo substrato o mesmo substrato utilizado na semeadura, desinfestado (formol $7 \%$ ), irrigado diariamente de forma manual (100 ml/planta). Cada tratamento com MAs também foi isolado com sacos de polietileno, afim de evitar contaminação entre espécies de MAs. Após 480 DAS, foram realizadas as avaliações das mudas considerando-se a altura $(\mathrm{cm})$, desde o colo até o ápice; o diâmetro $(\mathrm{cm})$ do colo da planta; o número de folhas; a área foliar (com auxílio de medidor de área foliar marca LI-COR, modelo LI - 3100) por planta $\left(\mathrm{cm}^{2}\right)$; o número de brotações; as massas (g) fresca e seca de raízes e parte aérea (secagem em estufa $65^{\circ} \mathrm{C}$ até atingir massa constante) e a razão entre área foliar e número de folhas por planta.

Também se fez a determinação do teor de substâncias de reserva nos tecidos, por meio da coleta de amostras da parte aérea das plantas, acondicionando-as em sacos de papel para secagem em estufa a $65^{\circ} \mathrm{C}$, até massa constante. Na sequência, o material foi moído em moinho e novamente acondicionado em pequenos saquinhos feitos de tela especial para filtragem de alimentos, contendo $1,5 \mathrm{~g}$ de amostra e amarrados com fio de nylon para impedir a perda de material. Após serem individualmente identificados, novamente foram levados à estufa a $65^{\circ} \mathrm{C}$, até massa 
constante. Os saquinhos com material vegetal foram então submetidos ao processo de digestão, para extração da substância de reserva e produtos sintetizados pelas plantas (carboidratos, gorduras e ácidos graxos), permanecendo somente as fibras (adaptado de PRIESTLEY, 1965). Nesta etapa, as amostras foram imersas em solução aquosa contendo $5 \%$ de ácido tricloroacético (99\% PA) e 35\% de metanol (99,8\% PA), em Erlenmayer de 1 L, permanecendo sob aquecimento em bico de Bunsen, em capela com exaustor, por 8 horas. Nas primeiras duas horas manteve-se em ebulição, após, manteve-se o nível da solução adicionando-se água destilada, até atingir as 8 horas. Ao final do processo, as amostras foram lavadas com água destilada e secas em estufa a $65^{\circ} \mathrm{C}$, até massa constante. Sendo o teor de reservas (\%) definido pela diferença de massa das amostras antes e após o processo de digestão.

O delineamento experimental foi o de blocos ao acaso em esquema de parcelas subdivididas 4 x 3 (MAs x espécies frutíferas) com três repetições com 10 mudas cada. As médias observadas foram diferenciadas pelo teste de Duncan ( $\mathrm{p}>0,05)$.

Para verificar a colonização por MAs, raízes de cada espécie vegetal foram coletadas e fixadas em solução de formaldeído, álcool e ácido acético (FAA), até a análise. Após a fixação adotou-se o seguinte protocolo para descoloração e tinção das raízes: as raízes foram cortadas em frações de aproximadamente $1 \mathrm{~cm}$ de comprimento. Estas foram submersas em hidróxido de potássio e submetidos ao banho-maria a $90^{\circ} \mathrm{C}$ por 15 minutos; a seguir, passaram por tríplice lavagem, com água destilada. Na sequência, passaram por dupla lavagem com hipoclorito de sódio (pH entre 3,0 e 3,7) e água destilada intercaladamente. Novamente, as raízes foram ao banho-maria com solução de hidróxido de potássio a $90^{\circ} \mathrm{C}$, por 15 minutos, seguida de tríplice lavagem com água destilada. Para coloração utilizou-se o corante azul de tripano, em capela de exaustão, em banho por 15 minutos, a $90^{\circ} \mathrm{C}$. Por fim, as raízes coradas passaram por dupla lavagem com água destilada e confeccionadas as lâminas para visualização em estereomicroscópio, com aumento de 40x. Para cada tratamento foram avaliadas três repetições de 20 segmentos de raízes de $1 \mathrm{~cm}$. Como critério de avaliação da presença das estruturas dos fungos (hifas, vesículas e arbúsculos) utilizou-se a seguinte escala: 0: ausência; 1: de 1 a 49 estruturas; 2: de 50 a 99 estruturas e 3: mais de 100 estruturas. As médias observadas foram diferenciadas pelo teste de Duncan ( $p>0,05)$.

\section{Resultados e discussão}

$\mathrm{Na}$ fase inicial de cultivo não foram observadas diferenças significativas entre as plantas inoculadas com as micorrizas arbusculares (MAs) e a testemunha, tanto para emergência, quanto para desenvolvimento inicial. Apesar de ter ocorrido colonização, a ineficácia das MAs na fase inicial de cultivo deve-se ao pouco tempo de ocorrência da colonização, além de as sementes de Myrtaceae possuírem cotilédones que suprem a necessidade inicial de substâncias necessárias à emergência das plantas. A associação da planta com as MAs na etapa de emergência de plântulas somente é fundamental quando se trata de sementes desprovidas de tecidos de reserva (PETERSON; MASSICOTTE; MELVILLE, 2004; DEARNALEY, 2007).

Aos 480 dias após a transferência para sacos de polietileno de $5 \mathrm{~L}$, a presença de MAs, independentemente da espécie, proporcionou incrementos em todas as variáveis avaliadas, exceto no diâmetro de caule, no número de brotações para Araçá e na altura para Guabiju (Tabela 1). Quando comparadas à testemunha, as inoculações proporcionaram incrementos médios na ordem de 135\% para altura, 195\% para número de folhas, 299\% para número de brotações e $209 \%$ para área foliar, independentemente da espécie de MA (Tabela 1). 
Tabela 1 - Altura, diâmetro do colo, número de folhas, número de brotações, área foliar, massa fresca e seca de raiz e parte aérea, razão entre área foliar total e número de folhas total em espécies de Myrtaceae cultivadas em substratos com diferentes endomicorrizas, 480 dias após a semeadura.

Table 1 - Height, lap diameter, number of leaves, number of shoots and leaf area, fresh and dry mass of root and shoot, ratio between total leaf area and total leaf number in Myrtaceae species grown on substrates with different endomycorrhizae, 480 days after sowing.

\begin{tabular}{|c|c|c|c|c|c|c|c|c|c|c|c|c|c|}
\hline Araçazeiro & \multicolumn{2}{|c|}{ Testemunha } & \multicolumn{2}{|c|}{$\begin{array}{c}\text { Glomus } \\
\text { etunicatum }\end{array}$} & \multicolumn{2}{|c|}{$\begin{array}{c}\text { Scutellospora } \\
\text { heterogama }\end{array}$} & \multicolumn{2}{|c|}{$\begin{array}{l}\text { Gigaspora } \\
\text { margarita }\end{array}$} & \multicolumn{2}{|c|}{$\begin{array}{c}\text { CV }(\%) \\
\text { entre } \\
\text { micorrizas }\end{array}$} & \multicolumn{2}{|c|}{$\begin{array}{l}\text { Média } \\
\text { entre } \\
\text { plantas }\end{array}$} & $\begin{array}{c}\text { CV }(\%) \\
\text { entre } \\
\text { plantas }\end{array}$ \\
\hline Altura $(\mathbf{c m})$ & 7.02 & $\mathrm{C}$ & 13.08 & A & 9,76 & $\mathrm{BC}$ & 12.22 & $\mathrm{AB}$ & 37.61 & $* * *$ & 9,98 & $\mathrm{~b}$ & $26,11^{*}$ \\
\hline $\begin{array}{l}\text { Diâmetro } \\
(\mathbf{m m})\end{array}$ & 1.99 & & 1.99 & & 1,66 & & 2.03 & & 31.22 & ns & 1,76 & $\mathrm{~b}$ & $28,85^{*}$ \\
\hline $\begin{array}{l}\text { Número de } \\
\text { Folhas }\end{array}$ & 8.21 & B & 18.72 & A & 13,88 & A & 18.64 & A & 20.38 & $* * *$ & 13,56 & c & $19,93^{*}$ \\
\hline $\begin{array}{l}\text { Número de } \\
\text { Brotações }\end{array}$ & 1.00 & & 0.94 & & 0,83 & & 0.94 & & 18.04 & ns & 0,65 & c & $22,41^{*}$ \\
\hline $\begin{array}{l}\text { Área Foliar } \\
\left(\mathbf{c m}^{2}\right)\end{array}$ & 16.71 & B & 69.37 & A & 39,87 & B & 68.95 & A & 35.04 & $* * *$ & 46,28 & c & $24,41^{*}$ \\
\hline $\begin{array}{l}\text { Massa Fresca } \\
\text { Raiz (g) }\end{array}$ & 0.23 & B & 1.30 & A & 0,59 & B & 0.79 & B & 86.00 & $* * *$ & 0,69 & $\mathrm{~b}$ & $16,23^{*}$ \\
\hline $\begin{array}{l}\text { Massa Fresca } \\
\text { P.A. (g) }\end{array}$ & 0.27 & B & 1.29 & A & 0,65 & B & 1.35 & A & 18.08 & $* * *$ & 0,85 & c & $15,79^{*}$ \\
\hline $\begin{array}{l}\text { Massa Seca } \\
\text { Raiz }(g)\end{array}$ & 0.09 & B & 0.35 & A & 0,18 & B & 0.22 & B & 6.24 & $* * *$ & 0,20 & $\mathrm{~b}$ & $7,45^{*}$ \\
\hline $\begin{array}{l}\text { Massa Seca } \\
\text { P.A. (g) }\end{array}$ & 0.07 & B & 0.29 & A & 0,17 & B & 0.37 & A & 6.78 & $* * *$ & 0,39 & c & $10,90^{*}$ \\
\hline $\mathrm{AF} / \mathrm{NF}$ & 1.79 & B & 3.58 & A & 2,8 & B & 3.72 & A & 18.49 & $* *$ & 2,78 & b & $35,63^{*}$ \\
\hline \multicolumn{14}{|l|}{ Uvaieira } \\
\hline Altura $(\mathbf{c m})$ & 27.08 & & 29.13 & & 31.47 & & 28.97 & & 19.92 & ns & 28,79 & $\mathrm{a}$ & \\
\hline $\begin{array}{l}\text { Diâmetro } \\
(\mathbf{m m})\end{array}$ & 2.87 & & 3.31 & & 3.12 & & 2.92 & & 20.69 & ns & 3,02 & $\mathrm{a}$ & \\
\hline $\begin{array}{l}\text { Número de } \\
\text { Folhas }\end{array}$ & 62.94 & B & 111.94 & A & 107.66 & A & 107.22 & A & 30.18 & $* * *$ & 96,59 & $\mathrm{a}$ & \\
\hline $\begin{array}{l}\text { Número de } \\
\text { Brotações }\end{array}$ & 4.23 & B & 11.16 & A & 8.77 & A & 10.66 & A & 19.05 & $* * *$ & 8,65 & $\mathrm{a}$ & \\
\hline $\begin{array}{l}\text { Área Foliar } \\
\left(\mathbf{c m}^{2}\right)\end{array}$ & 118.63 & B & 149.39 & $\mathrm{AB}$ & 188.08 & A & 165.4 & A & 36.90 & $* *$ & 153,73 & b & \\
\hline $\begin{array}{l}\text { Massa Fresca } \\
\text { Raiz (g) }\end{array}$ & 0.72 & B & 1.74 & A & 1.41 & A & 1.47 & A & 25.26 & $* *$ & 1,33 & $\mathrm{a}$ & \\
\hline $\begin{array}{l}\text { Massa Fresca } \\
\text { P.A. (g) }\end{array}$ & 1.56 & B & 2.58 & A & 2.78 & A & 2.61 & A & 36.82 & $* * *$ & 2,36 & $\mathrm{~b}$ & \\
\hline
\end{tabular}


Tabela 1 - Conclusão ...

Table 1 - Conclusion ...

\begin{tabular}{|c|c|c|c|c|c|c|c|c|c|c|c|c|c|}
\hline \multirow[b]{2}{*}{$\begin{array}{l}\text { Massa Seca } \\
\text { Raiz (g) }\end{array}$} & \multicolumn{2}{|c|}{ Testemunha } & \multicolumn{2}{|c|}{$\begin{array}{c}\text { Glomus } \\
\text { etunicatum }\end{array}$} & \multicolumn{2}{|c|}{$\begin{array}{c}\text { Scutellospora } \\
\text { heterogama }\end{array}$} & \multicolumn{2}{|c|}{$\begin{array}{l}\text { Gigaspora } \\
\text { margarita }\end{array}$} & \multicolumn{2}{|c|}{$\begin{array}{c}\text { CV }(\%) \\
\text { entre } \\
\text { micorrizas }\end{array}$} & \multicolumn{2}{|c|}{$\begin{array}{l}\text { Média } \\
\text { entre } \\
\text { plantas }\end{array}$} & \multirow[t]{2}{*}{$\begin{array}{l}\text { CV (\%) } \\
\text { entre } \\
\text { plantas }\end{array}$} \\
\hline & 0.31 & B & 0.62 & A & 0.58 & A & 0.49 & A & 18.10 & * & 0,49 & $\mathrm{a}$ & \\
\hline $\begin{array}{l}\text { Massa Seca } \\
\text { P.A. (g) }\end{array}$ & 0.67 & B & 1.09 & A & 1.31 & A & 1.09 & A & 37.25 & $* * *$ & 1,08 & $\mathrm{~b}$ & \\
\hline $\mathrm{AF} / \mathrm{NF}$ & 1.97 & A & 1.37 & B & 1.78 & $A B$ & 1.57 & $\mathrm{AB}$ & 33.43 & * & 1,65 & c & \\
\hline \multicolumn{14}{|l|}{ Guabijuzeiro } \\
\hline Altura (cm) & 24.11 & B & 31.7 & A & 34.00 & A & 32.88 & A & 17.93 & $* * *$ & 30,23 & $\mathrm{a}$ & \\
\hline $\begin{array}{l}\text { Diâmetro } \\
(\mathbf{m m})\end{array}$ & 2.73 & & 2.82 & & 3.20 & & 3.25 & & 22.17 & ns & 2,96 & $\mathrm{a}$ & \\
\hline $\begin{array}{l}\text { Número de } \\
\text { Folhas }\end{array}$ & 17.05 & $\mathrm{C}$ & 32.58 & A & 25.00 & B & 28.95 & $\mathrm{AB}$ & 11.91 & $* * *$ & 25,51 & $\mathrm{~b}$ & \\
\hline $\begin{array}{l}\text { Número de } \\
\text { Brotações }\end{array}$ & 1.05 & B & 3.29 & A & 2.41 & A & 2.94 & A & 24.29 & $* * *$ & 2,38 & $\mathrm{~b}$ & \\
\hline $\begin{array}{l}\text { Área Foliar } \\
\left(\mathbf{c m}^{2}\right)\end{array}$ & 110.76 & B & 292.47 & A & 236.95 & A & 249.47 & B & 30.95 & $* * *$ & 218,30 & $\mathrm{a}$ & \\
\hline $\begin{array}{l}\text { Massa Fresca } \\
\text { Raiz (g) }\end{array}$ & 0.63 & $\mathrm{C}$ & 2.37 & A & 1.65 & B & 1.53 & A & 15.43 & $* \star *$ & 1,51 & $\mathrm{a}$ & \\
\hline $\begin{array}{l}\text { Massa Fresca } \\
\text { P.A. (g) }\end{array}$ & 2.05 & $\mathrm{C}$ & 5.58 & A & 4.40 & B & 5.59 & B & 33.58 & $* * *$ & 4,33 & $\mathrm{a}$ & \\
\hline $\begin{array}{l}\text { Massa Seca } \\
\text { Raiz }(\mathbf{g})\end{array}$ & 0.28 & $\mathrm{C}$ & 0.75 & A & 0.53 & B & 0.52 & A & 7.03 & $* \star *$ & 0,51 & $\mathrm{a}$ & \\
\hline $\begin{array}{l}\text { Massa Seca } \\
\text { P.A. (g) }\end{array}$ & 0.90 & B & 2.41 & A & 1.95 & A & 2.26 & A & 33.58 & $\star \star \star *$ & 1,90 & $\mathrm{a}$ & \\
\hline $\mathrm{AF} / \mathrm{NF}$ & 6.44 & B & 8.89 & A & 9.69 & A & 8.61 & A & 19.12 & $* * *$ & 8,28 & $\mathrm{a}$ & \\
\hline
\end{tabular}

Em que: $\mathrm{AF} / \mathrm{NF}$ = razão entre área foliar total e número de folhas total; P.A. = Parte aérea; $\mathrm{CV}(\%)=$ Coeficiente de variação. Médias seguidas de mesma letra, maiúscula na linha, não diferem estatisticamente (Duncan 5\%); Médias seguidas de mesma letra, minúscula na coluna, comparam as espécies vegetais e não diferem estatisticamente (Duncan 5\%) ns = diferença não significativa pelo teste de Duncan. ${ }^{* * *}$ Diferença significativa pelo teste de Duncan $(p>0,05$ respectivamente).

A eficiência das MAs após o transplante para recipientes de $5 \mathrm{~L}$ confirmou a importância do tempo de colonização e do volume do recipiente para que as mesmas pudessem expressar todo o seu potencial. Enquanto algumas MAs colonizam rapidamente o hospedeiro e produzem abundante esporulação, outras necessitam de mais tempo para esporular ou esporulam pouco e persistem no ambiente, principalmente na forma ativa, e não como esporo (GOMIDE et al., 2009). Conforme o observado por Silveira; Souza; Koller (2002) que ao estudarem os efeitos de micorrizas arbusculares (Glomus clarum, Glomus etunicatum, Glomus manihotis, Acaulospora scrobiculata, Scutellospora heterogama e Gigaspora margarita) em mudas de abacateiro (Persea americana Mill.) nas fases de porta-enxerto, de muda enxertada e de pomar, verificaram que a presença de hifas, vesículas e arbúsculos nos diversos tratamentos foi mais elevada somente na segunda fase (muda enxertada), em comparação com a primeira. Segundo os autores, este comportamento era esperado e deve-se, principalmente, ao maior período de cultivo das mudas 
em seus respectivos recipientes, além do maior volume destes, permitindo maior exploração da rizosfera por parte das MAs.

A área foliar é um importante parâmetro, por definir a taxa de fotossíntese realizada na planta, que resulta na maior ou menor produção de fotoassimilados (CAVALCANTE et al., 2001). Silva et al. (2004) afirmaram que o aumento da taxa fotossintética de plantas inoculadas com MAs, está diretamente relacionado com o aumento da área foliar, o que proporciona aumento do crescimento vegetativo e acúmulo de biomassa fresca e seca. Somente foram observadas interações nas variáveis: número de folhas $(\mathrm{p}>0,001)$ e área foliar $(\mathrm{p}>0,001)$, sendo que Uvaieira obteve o melhor desempenho para número de folhas, enquanto Guabijuzeiro teve melhor desempenho para área foliar, independentemente da MA estudada nas duas situações (Tabela 1).

Ao serem comparadas as espécies vegetais, o maior desenvolvimento vegetativo (especialmente altura, diâmetro de colo, número de folhas e de brotações) foi observado nas mudas de Uvaieira, seguida de Guabijuzeiro (Tabela 1), devido principalmente às diferenças em vigor características das espécies.

As massas fresca e seca de raiz e parte aérea e a relação entre área foliar e número de folhas, também foram incrementadas na presença de MAs, com destaque para Glomus etunicatum, principalmente em massa fresca e seca de raiz, para massa fresca de parte aérea Gigaspora margarita juntamente com Glomus etunicatum foram os de melhor desempenho, não diferindo estatisticamente (Tabela 1). Entre as espécies vegetais, para as mesmas variáveis, houve destaque do Guabijuzeiro, embora não tenha diferenciado significativamente de Uvaieira em massa fresca e seca de raiz e parte aérea. Silveira; Souza; Koller (2002) também observaram incremento em massa de parte aérea na produção de mudas de Abacateiro (Persea americana Mill.) inoculadas com MAs.

A análise de interação foi significativa para massa fresca de parte aérea $(\mathrm{p}>0,001$, para ambas), sendo Guabijuzeiro inoculado com Gigaspora margarita e Glomus etunicatum as melhores combinações. Para massa seca de parte aérea e na relação $\mathrm{AF} / \mathrm{NF}$ a interação apontou melhor resultado significativo ( $\mathrm{p}>0,001)$ para guabijuzeiro, independente da MAs inoculada (Tabelas 1).

Uvaieira apresentou maior teor de substâncias de reservas, seguida de Araçazeiro e, por fim, de Guabijuzeiro (Figura 1). Entre as MAs, Gigaspora margarita foi a que proporcionou maior incremento às espécies vegetais utilizadas, embora não tenha se diferenciado da testemunha. $\mathrm{O}$ fato de as MAs causarem desenvolvimento vegetativo diferenciado, quando inoculadas em frutíferas, está associado à afinidade, maior ou menor, que cada espécie de MA tem com a espécie vegetal utilizada, que estaria relacionada à existência de uma compatibilidade funcional entre o hospedeiro e o fungo (SCHREINER, 2007). Nas combinações testadas, Gigaspora margarita para esta variável teve melhor desempenho que as demais MAs. Em Guabijuzeiro, observouse redução no teor de substâncias de reservas, assim como em Uvaieira e Araçazeiro quando inoculadas com Scutellospora heterogama e Glomus etunicatum (Figura 1). Este comportamento pode ser devido à necessidade de um período mais longo para ocorrer a interação entre MAs e as raízes destas espécies, o que acarretaria em um desgaste de reservas da planta já que até a completa colonização das MAs, há o consumo de reservas da planta para promover o seu estabelecimento (NOGUEIRA, 2001).

Da mesma forma, Anzanello; Souza; Casamali (2011) trabalhando com a interação entre MAs, e porta-enxertos de Videira relataram compatibilidade funcional entre os simbiontes estudados onde maior massa fresca e seca foram observadas nas combinações dos porta-enxertos Paulsen 1103 e SO4 quando inoculadas com Glomus etunicatum e Scutellospora heterogama. Os benefícios dessa simbiose também foram registrados por outros autores, que relataram que o estímulo ao crescimento vegetal se deve a fatores nutricionais, principalmente ao aumento da absorção de nitrogênio (COSTA; LOVATO, 2004; SILVEIRA, 2006), fósforo (NUNES et al., 2008) e potássio (SILVEIRA; SOUZA; KOLLER, 2002; CALVET et al.,2003). 
Figura 1 - Substâncias de reserva em espécies de Myrtaceae cultivadas em substratos com diferentes endomicorrizas, $\mathbf{4 8 0}$ dias após a semeadura. (Sobre a coluna, mesma letra, maiúscula entre as espécies vegetais e letras minúscula entre as endomicorrizas não diferem significativa pelo teste de Duncan $(p>0,05))$.

Figure 1 - Substances of reserve in species of Myrtaceae grown on substrates with different endomycorrhizae, 480 days after sowing. (On the column, the same capital letter between plant species and lower case letters between endomycorrhizae do not differ significantly by Duncan's test $(\mathrm{p}>0.05))$.

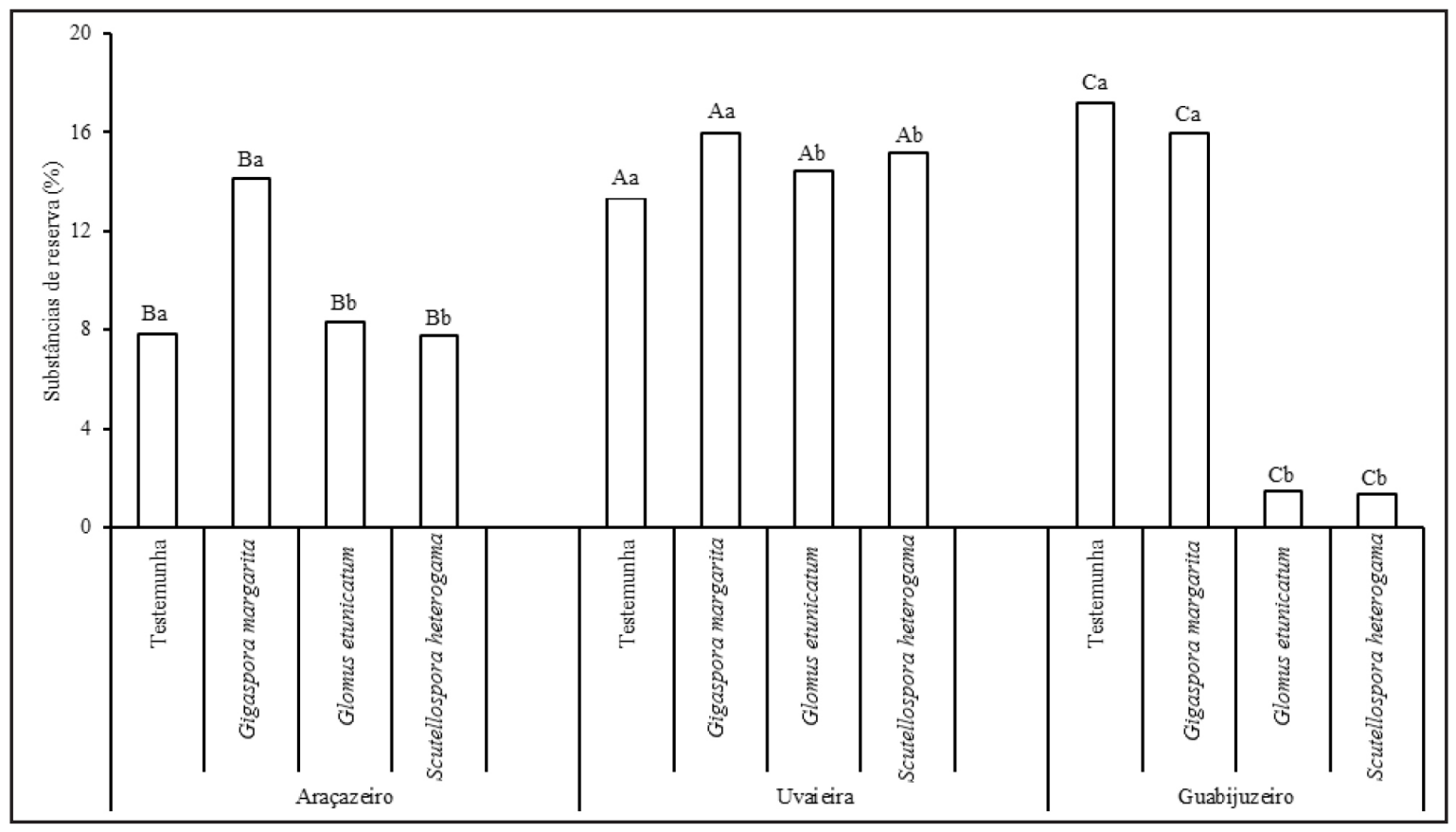

Fonte: Autores (2019)

Quando inoculados artificialmente, independentemente da espécie vegetal e da MA, observou-se mais de $89 \%$ de colonização por endomicorrizas em raízes, comprovando a eficiência da simbiose, sendo este valor três vezes superior à testemunha (Tabela 2). Nas plantas testemunha observou-se alguma presença de micorrizas colonizando as raízes, que pode estar associada à eficiência parcial do formaldeído usado para desinfestação do substrato e/ou por contaminação decorrente do transporte de esporos por formigas que visitaram as plantas durante o período de experimento. Contudo, trata-se de níveis aceitáveis de contaminação já relatados em outros estudos (SILVEIRA; SOUZA; KOLLER, 2002).

Houve interação entre a presença de hifas e a espécie vegetal, sendo as combinações de Scutellospora heterogama e Gigaspora margarita quando inoculadas em Guabijuzeiro as de melhor desempenho (Tabela 2). Entretanto, estas mesmas combinações apresentaram pior desempenho em percentual de substâncias de reserva (Figura 1), o que indica que houve maior investimento de reservas pela planta para promover a simbiose com estas MAs. Ainda assim, a presença de hifas pode ter contribuído para o desenvolvimento vegetativo das plantas (Tabela 1), pois de acordo com Siqueira; Lambais; Stürmer (2002), as hifas externas de MAs possibilitam, ao sistema radicular das plantas hospedeiras, maior assimilação de nutrientes, já que aumentam a área de solo a ser explorada. Portanto, até a completa simbiose entre estas MAs e Guabijuzeiro provavelmente tenha ocorrido o consumo de reservas da planta e, após completada a simbiose, as hifas promoveram um desenvolvimento vegetativo acelerado, não havendo tempo hábil para o incremento em substâncias de reserva (Tabela 1 e Figura 1). 
Tabela 2 - Percentual de colonização, índice de presença de hifas, vesículas e arbúsculos e percentual de carboidratos em espécies de Myrtaceae cultivadas em substratos com diferentes endomicorrizas, $\mathbf{4 8 0}$ dias após a semeadura.

Table 2 - Percentage of colonization, index of presence of hyphae, vesicles and arbulosis and percentage of carbohydrates in species of Myrtaceae grown on substrates with different endomycorrhizae, 480 days after sowing.

\begin{tabular}{|c|c|c|c|c|c|c|c|}
\hline \multirow{2}{*}{ Tratamentos } & \multicolumn{6}{|c|}{ \% Colonização } & \\
\hline & \multicolumn{2}{|c|}{ Uvaieira } & \multicolumn{2}{|c|}{ Araçazeiro } & \multicolumn{2}{|c|}{ Guabijuzeiro } & \\
\hline Testemunha & \multicolumn{2}{|c|}{$18,00 \mathrm{~A} \mathrm{~b}$} & \multicolumn{2}{|c|}{$38,00 \mathrm{~A} \mathrm{~b}$} & \multicolumn{2}{|c|}{$10,00 \mathrm{~B} \mathrm{~b}$} & \\
\hline Glomus etunicatum & \multicolumn{2}{|c|}{$88,88 \mathrm{~A}$ a } & \multicolumn{2}{|c|}{$96,33 \mathrm{~A} \mathrm{a}$} & \multicolumn{2}{|c|}{$95,83 \mathrm{~A}$ a } & \\
\hline Scutellospora heterogama & \multicolumn{2}{|c|}{$95,83 \mathrm{~A} \mathrm{a}$} & \multicolumn{2}{|c|}{$92,00 \mathrm{~A}$ a } & \multicolumn{2}{|c|}{$100,00 \mathrm{~A} \mathrm{a}$} & \\
\hline Gigaspora margarita & \multicolumn{2}{|c|}{$75,00 \mathrm{~A} \mathrm{a}$} & \multicolumn{2}{|c|}{$92,16 \mathrm{~A}$ a } & \multicolumn{2}{|c|}{$100,00 \mathrm{~A} \mathrm{a}$} & \\
\hline CV (\%) & \multicolumn{6}{|c|}{12,41} & \\
\hline \multirow[t]{2}{*}{ Interação $\mathbf{p} \geq \mathbf{0 , 0 5}$} & \multicolumn{6}{|c|}{0,014} & \\
\hline & \multicolumn{6}{|c|}{ Hifas } & \\
\hline Testemunha & \multicolumn{2}{|c|}{$0,18 \mathrm{~B} \mathrm{~b}$} & \multicolumn{2}{|c|}{0,43 A c } & \multicolumn{2}{|c|}{$0,16 \mathrm{~B} \mathrm{c}$} & \\
\hline Glomus etunicatum & \multicolumn{2}{|c|}{$1,66 \mathrm{~A} \mathrm{a}$} & \multicolumn{2}{|c|}{$0,96 \mathrm{~B} \mathrm{~b}$} & \multicolumn{2}{|c|}{$1,30 \mathrm{AB} b$} & \\
\hline Scutellospora heterogama & \multicolumn{2}{|c|}{$1,44 \mathrm{~B} \mathrm{a}$} & \multicolumn{2}{|c|}{$1,36 \mathrm{~B} \mathrm{a}$} & \multicolumn{2}{|c|}{$2,68 \mathrm{~A} \mathrm{a}$} & \\
\hline Gigaspora margarita & 1,44 & & $1,15 \mathrm{~B}$ & & $2,95 \mathrm{~A}$ & & \\
\hline CV (\%) & & & & & & & \\
\hline Interação $p \geq 0,05$ & & & & & & & \\
\hline & & & Ves & las & & & Média \\
\hline Testemunha & 0,1 & & 0,05 & & 0,06 & & $0,36 \mathrm{c}$ \\
\hline Glomus etunicatum & 0,6 & & 0,48 & & 0,56 & & $1,80 \mathrm{~b}$ \\
\hline Scutellospora heterogama & 0,6 & & 0,80 & & 0,60 & & $2,32 \mathrm{a}$ \\
\hline Gigaspora margarita & 0,5 & & 0,57 & & 0,70 & & $2,16 \mathrm{ab}$ \\
\hline Média & 0,49 & $\mathrm{a}$ & 0,47 & a & 0,48 & $\mathrm{a}$ & \\
\hline CV (\%) & & & & 33,52 & & & \\
\hline Interação p $\geq 0,05$ & & & & 0,52 & & & \\
\hline & & & Arbúsc & & & & \\
\hline Testemunha & 0,24 & $\mathrm{~B} \mathrm{~b}$ & 0,67 & C a & 0,16 & B c & \\
\hline Glomus etunicatum & 1,89 & A a & 1,22 & $\mathrm{BC} \mathrm{b}$ & 2,30 & A a & \\
\hline Scutellospora heterogama & 2,24 & A a & 1,93 & $\mathrm{~A} a \mathrm{~b}$ & 2,80 & A a & \\
\hline Gigaspora margarita & 1,80 & A a & 1,68 & $\mathrm{AB}$ a & 3,00 & A a & \\
\hline CV (\%) & & & & 28,07 & & & \\
\hline Interação $p \geq 0,05$ & & & & 0,401 & & & \\
\hline
\end{tabular}

Em que: $C V(\%)$ = Coeficiente de Variação. Mesmas letras maiúsculas na coluna e minúsculas nas linhas não diferem pelo teste de Duncan ( $p>0,01$, respectivamente). Ns = diferença não significativa pelo teste de Duncan. 
Para presença de arbúsculo também houve interação entre os tratamentos, sendo novamente o Guabijuzeiro o de melhor desempenho, independentemente da MA utilizada (Tabela 2). Nas condições deste estudo, as respostas diferenciadas em desenvolvimento de plantas, observadas entre as Myrtaceae estudadas, segundo a espécie de MAs inoculada, são devidas à compatibilidade funcional entre os simbiontes, assim como o relatado em outros trabalhos (LOCATELLI; LOVATO, 2002; SILVEIRA; SOUZA; KOLLER, 2002; ANZANELLO; SOUZA; CASAMALI, 2011).

Os resultados obtidos confirmam que as micorrizas arbusculares estudadas possuem afinidade com as Myrtaceae, podendo ser incluídas em programas de produção de mudas destas espécies, a fim de acelerar e melhorar o desenvolvimento das plantas.

\section{Conclusão}

A simbiose entre mudas de Araçazeiro, Uvaieira e Guabijuzeiro com Glomus etunicatum, Gigaspora margarita e Scutellospora heterogama é efetiva independentemente da espécie, permitindo acelerar o período de formação das mudas.

Uvaieira apresenta desenvolvimento inicial mais acelerado, que mais tarde é alcançado por Guabijuzeiro; com Araçazeiro apresentando desenvolvimento mais lento em relação aos anteriores.

\section{Referências}

AGUIAR, R. L.F.etal. Interação entre fungos micorrízicos arbusculares e fósforo no desenvolvimento da Algaroba [Prosopis juliflora (SW) DC]. Revista Árvore. Viçosa, v. 28, p.589-598. 2004.

ANZANELLO, R.; SOUZA, P. V. D.; CASAMALI, B. Fungos micorrízicos arbusculares (FMA) em porta-enxertos micropropagados de videira. Bragantia, Campinas, v. 70, n. 2, p.409-415, 2011

BRUNDRETT, M.; MELVILLE, L.; PETERSON, L. Practical methods in mycorrhiza research. Ontário: Mycologue Publications, 1994. 80p.

CALVET, C. et al. A. Aptitude for mycorrhizal root colonization in Prunus rootstocks. Scientia Horticulturae [s.1.], v. 9, p.1-10. 2003.

CAMPOS, D. T. S. et al. Colonização micorrízica em plantios de eucalipto. Revista Árvore.Viçosa,v. 35 n.5, p. 965-974, 2011.

CAVALCANTE, U. M. T. etal. Respostas fisiológicas em mudas de maracujazeiro amarelo (Passiflora edulis Sims. f. flavicarpa Deg.) inoculadas com fungos micorrízicos arbusculares e submetidas a estresse hídrico. Acta Botanica Brasilica. Belo Horizonte, v. 15, n. 3, p. 379-390. 2001.

COSTA, M. D.; LOVATO, P. E. Fosfatases na dinâmica do fósforo do solo sob culturas de cobertura com espécies micorrízicas e não micorrízicas. Pesquisa Agropecuária Brasileira, Brasília, v.39, p.603-605, 2004.

DEARNALEY, J.D.W. Further advances in orchid mycorrhizal research.Mycorrhiza. Oregon, v. 17, p. $475-486,2007$.

RASEIRA, M.C.B. et al. Espécies frutíferas nativas do sul do Brasil. Pelotas: Embrapa Clima Temperado, 2004. $122 \mathrm{p}$.

GOMIDE, P. H. O. et al. Diversidade e função de fungos micorrízicos arbusculares em sucessão de espécies hospedeiras. Pesquisa Agropecuária Brasileira, Brasilia, v. 44, n. 11, p. 1483-1490, 2009.

JOSÉ, A.C.; DAVIDE, A.C.; OLIVEIRA, S.L. Produção de mudas de aroeira (Schinustere binthifolius Raddi) para recuperação de áreas degradadas pela mineração bauxita. Cerne, Lavras, v. 11, n. 2, p. 
187-196, 2005.

LOCATELLI, L. M.; LOVATO, P. E. Inoculação micorrízica e aclimatização de dois porta-enxertos de macieira micropropagados. Pesquisa Agropecuária Brasileira, Brasília, v. 37, p.177-184. 2002.

LOPES, P.Z. Propagação vegetativa e interação com endomicorrizas arbusculares em mirtáceas nativas do Sul do Brasil. 2009. 134f. Tese (Doutorado em Fitotecnia) - Universidade Federal do Rio Grande do Sul. Porto Alegre, 2009.

MANICA, I. Frutas nativas, silvestres e exóticas 2: Técnicas de produção e mercado: feijao, figoda-índia, fruta-pão, jaca, lichia, mangaba. Porto Alegre: Cinco Continentes, 2002. 541 p.

NOGALES, A. et al. Response of mycorrhizal grapevine to Armillaria mellea inoculation: disease development and polyamines. Plant and Soil, [s.l.], v.317, p.177-187, 2009.

NOGUEIRA, M.A. Interações entre micorriza arbuscular, rizobacbérias, fósforo e silício na manifestação da toxidez de manganês em soja. 2001. 195 f. Tese (Doutorado em Agronomia) Escola Superior de Agricultura Luiz de Queiroz, 2001.

NUNES, J.L.S. et al. Inoculação de fungos micorrízicos arbusculares em porta-enxerto de pessegueiro cv Okinawa. Revista Brasileira de Fruticultura, Jaboticabal, v.30, p.1100-1106, 2008.

PETERSON, R.L.; MASSiCOTTE, H.B.; MELVILle, L.H. Mycorrhizas: Anatomy and Cell biology. Ottawa, Canada, NRC Research Press. 2004. 173 p.

PRIESTLEY, G.A. New method for the estimation of the resources of apple trees. Journal of the Science of Food and Agriculture, v. 16, p. 717 - 721. 1965.

RAMOS, A.C. et al. An outlook on ion signaling and ionome of mycorrhizal symbiosis. Brazilian Journal of Plant Physiology, Campos dos Goytacazes, v. 23, p. 79-89. 2011.

SCHREINER, R.P. Effects of native and nonnative arbuscular mycorrhizal fungi on growth and nutrient uptake of "Pinot noir" (Vitis vinifera L.) in two soils with contrasting levels of phosphorus. Applied Soil Ecology, Amsterdam, v. 36, n. 2/3, p. 205-215, 2007.

SILVA, R. F. et al. Ocorrência de Fungos Micorrízicos em espécies florestais na região central do estado do Rio Grande do Sul. Revista Brasileira de Agrociência, Pelotas, v.15, n.1-4, p.65-70, jandez, 2009.

SILVA, M. A. et al. Crescimento de mudas de maracujazeiro-doce (Passiflora alata Curtis) associadas a fungos micorrízicos arbusculares (Glomeromycota). Acta Botanica Brasílica, Belo Horizonte, v. 18, p.981-985, 2004.

SILVA, R.P.; PEIXOTO, J.R.; JUNQUEIRA, N.T.V. Influência de diversos substratos no desenvolvimento de mudas de maracujazeiro azedo (Passiflora edulis Sims f. flavicarpa DEG). Revista Brasileira de Fruticultura, Jaboticabal, v. 23, n. 2, p. 377-381, 2001.

SILVEIRA, S. V.; SOUZA, P. V. D.; KOLLER, O. C. Influência de fungos micorrízicos arbusculares sobre o desenvolvimento vegetativo de porta-enxertos de abacateiro. Pesquisa Agropecuária Brasileira, Brasília, v. 37, p. 303-309, 2002.

SILVEIRA, S.V. Caracterização de micorrizas arbusculares autóctones de parreirais da serra gaúcha e otimização de métodos de multiplicação em espécies aromáticas para aplicação na fruticultura. 2006.129f. Tese (Doutorado em Fitotecnia) - Universidade Federal do Rio Grande do Sul, Porto Alegre, 2006.

SIQUEIRA, J. O.; LAMBAIS, M. R.; STÜRMER, S. L. Fungos micorrízicos arbusculares: origem e características dos fungos Glomaleanos. Biotecnologia, Ciência e Desenvolvimento, Brasília, v. 25 , p. 12-21, 2002. 